CORRIGENDUM

\title{
Central West Antarctica among the most rapidly warming regions on Earth
}

\author{
David H. Bromwich, Julien P. Nicolas, Andrew J. Monaghan, Matthew A. Lazzara, Linda M. Keller, \\ George A. Weidner and Aaron B. Wilson
}

Nature Geoscience 6, 139-145 (2013); published online 23 December 2012; corrected after print 23 December 2013.

In our Article presenting a reconstruction of the near-surface temperature record at Byrd Station, a calculation error led to an overestimation of the magnitude and statistical significance of the temperature trends in December-January shown in Fig. 3a,b and Supplementary Table S1. For 1958-2010, the 'DJ' trend should have been $0.34 \pm 0.24^{\circ} \mathrm{C}$ per decade, instead of $0.45 \pm 0.29^{\circ} \mathrm{C}$ per decade, although the significance remained unchanged at the $99 \%$ level $(P<0.01)$. For $1980-2010$, the trend

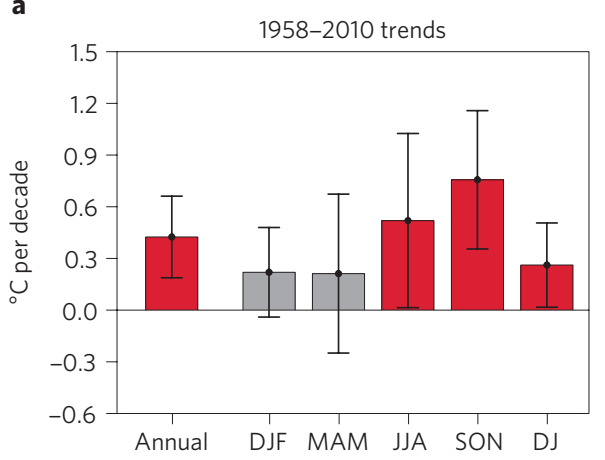

b

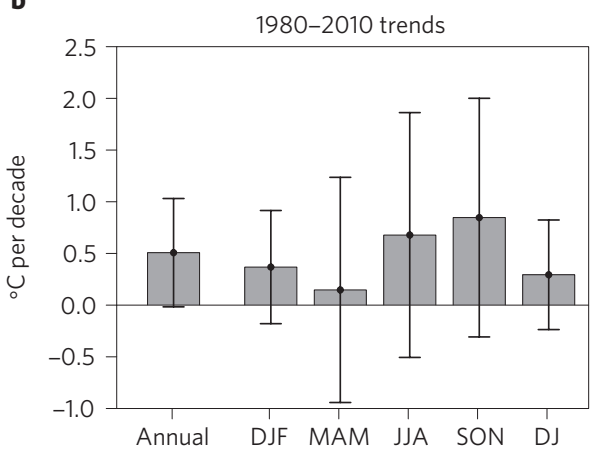

should have been $0.29 \pm 0.53^{\circ} \mathrm{C}$ per decade, instead of $0.76 \pm 0.66^{\circ} \mathrm{C}$ per decade, and thus was not statistically significant. As a result, the last sentence of the section entitled "Temperature trends at Byrd Station", referring to the significance of the trends during 1980-2010, should not include "except for December-January". This calculation error had no bearing on the other trends discussed in the paper.

Furthermore, the reconstruction was done, in part, by merging temperature observations from the staffed Byrd Station established in 1957 and occupied year-round until the early 1970s, with temperatures recorded by the automatic weather station in operation since 1980. These observations were based on monthly mean temperatures compiled by the Antarctic READER Project ${ }^{1}$. Whenever possible, READER uses six-hourly data to compute the monthly means in an effort to produce consistent meteorological time series for Antarctica. Because six-hourly data were not found for Byrd for the years 1957 to 1975, the monthly means reported by READER for this period were taken from a previous compilation of Antarctic temperatures ${ }^{2}$ based on monthly reports published in the Monthly Climatic Data for the World or the World Weather Records. One concern about these reports was the lack of information regarding the methodology used to derive the monthly means.

In early 2013, we discovered previously unused sub-daily meteorological observations from Byrd Station for the period 1957-75 on the website of the National Climatic Data Center. This data set had been available for a few years but was overlooked during our reconstruction efforts. Using this data, we have recalculated the monthly mean temperatures from 1957 to 1975 in a manner consistent with the more recent portion of the Byrd record. For the period running from October to March, the recalculation yields higher temperatures (by $0.3{ }^{\circ} \mathrm{C}$ on average) than those previously published by READER, with virtually no effect $\left(<0.1^{\circ} \mathrm{C}\right)$ during the rest of the year. These discrepancies are likely to stem from the use of daily minima and maxima for the monthly reports published in the 1950s to 1970 s, in conjunction with the effects of the diurnal cycle of air temperature during the sunlit part of the year. Both our temperature reconstruction (http://polarmet.osu.edu/Byrd_recon/) and the READER database have since been updated to incorporate these changes.

This update reduces the magnitude of the long-term warming trend at Byrd (Fig. 3a). The 1958-2010 annual trend is lowered by around $10 \%$ (from $0.47 \pm 0.23^{\circ} \mathrm{C}$ per decade to $0.42 \pm 0.24{ }^{\circ} \mathrm{C}$ ) but remains statistically significant at $99 \%$. The impact is greatest in austral summer (December-February) where the $1958-2010$ trend changes from $0.30 \pm 0.27^{\circ} \mathrm{C}$ per decade to $0.22 \pm 0.26^{\circ} \mathrm{C}$ per decade and loses its statistical significance. In December-January, the height of Antarctic summer when melting occurs episodically in West Antarctica, the new trend $\left(0.26 \pm 0.24^{\circ} \mathrm{C}\right.$ per decade) does remain significant, but at $95 \%$ instead of $99 \%$ (the comparison is with respect to the corrected trend of $0.34 \pm 0.24^{\circ} \mathrm{C}$ mentioned in the above first paragraph, which was calculated before updating the 1957-1975 temperatures). The trends in the other seasons are less affected and maintain their statistical significance (or lack thereof in March-May). Overall, the main finding of the study, namely that the total annual temperature increase at Byrd between 1958 and $2010\left(2.18 \pm 1.25^{\circ} \mathrm{C}\right)$ still ranks among the fastest warming rates on Earth, remains valid. Nevertheless, the corrected and updated trends reduce the emphasis initially placed on summer warming, thus making our results more consistent with other temperature reconstructions ${ }^{3,4}$. These revisions mark the latest episode in a decade-long process that has led to a more robust temperature record for a key outpost in West Antarctica ${ }^{3,5-9}$.

A version of Fig. 3a,b that accounts for the correction and update is reproduced above. Updated versions of tables and other figures as well as details about the temperature recalculation are provided in the Supplementary Information of the Corrigendum.

\section{References}

1. Turner, J. et al. J. Clim. 17, 2890-2898 (2004).

2. Jones, P. D. \& Reid, P. A. A Databank of Antarctic Surface Temperature and Pressure Data. (US Dept. Energy, 2001); http://go.nature.com/g2Txyi

3. Steig, E. J. et al. Nature 457, 459-462 (2009).

4. O’Donnell, R., Lewis, N., McIntyre, S. \& Condon, J. J. Clim. 24, 2099-2115 (2011).

5. Shuman, C. A. \& Stearns, C. R. J. Clim. 14, 1977-1988 (2001).

6. Reusch, D. B. \& Alley, R. B. J. Geophys. Res. 109, D04103 (2004).

7. Monaghan, A. J., Bromwich, D. H., Chapman, W. \& Comiso, J. C. J. Geophys. Res. 113, D04105 (2008).

8. Küttel, M., Steig, E. J., Ding, Q., Monaghan, A. J. \& Battisti, D. S. Clim. Dyn. 39, 1841-1857 (2012).

9. Bromwich, D. H. et al. Nature Geosci. 6, 139-145 (2013). 